\title{
DESCONTINUIDADE DE MEDICAMENTOS PELA INDÚSTRIA FARMACÊUTICA: A COLISÃo ENTRE O DIREITO À SAÚDE E A LÓGICA DE MERCADO
}

\author{
Cristiane Canisela Villalva Prado* \\ Victor Hugo Tejerina Velázquez ${ }^{* *}$
}

\begin{abstract}
RESUMO: O presente trabalho objetiva analisar a violação ao direito fundamental à saúde através da descontinuidade de produção de medicamentos mais antigos e de baixo custo pela indústria farmacêutica, alguns dos quais considerados essenciais e sem substitutos, além de identificar possíveis mecanismos de resolução. A ANVISA não dispõe de mecanismos que possam obrigar um laboratório a manter a produção destes medicamentos. No entanto, o desabastecimento do mercado farmacêutico não é exclusividade brasileira. Nesse sentido, o texto analisa as medidas tomadas pela agência reguladora argentina, a ANMAT, e também busca soluções a partir da Lei de Inovação.
\end{abstract}

Palavras-chave: Medicamentos; Descontinuidade; Anvisa; Indústria Farmacêutica; Lei de Inovação.

\section{DISCONTINUITY OF MEDICINES BY THE PHARMACEUTICAL INDUSTRY: THE COLLISION BETWEEN THE RIGHT TO HEALTH AND THE MARKET LOGIC}

\begin{abstract}
The present study aims to analyze the violation of the fundamental right to health through the discontinuity of production of older and cheaper drugs by the pharmaceutical industry, some of which are considered essential and without substitutes, and identify possible mechanisms of resolution. ANVISA does not have mechanisms that may require a laboratory to maintain the production of these drugs. However, the shortage of the pharmaceutical market is not Brazilian exclusivity. In this sense, the text analyzes measures taken by the Argentine regulatory agency, ANMAT, and also seeks solutions based on the Innovation Law.
\end{abstract}

Keywords: Medications; Discontinuity; Anvisa; Pharmaceutical Industry; Innovation Law.

\footnotetext{
* Mestranda em Direito pela Universidade Metodista de Piracicaba (UNIMEP). Bacharel em Direito pela Pontifícia Universidade Católica de Minas Gerais (PUC-Minas). Advogada. Farmacêutica-bioquímica pela Faculdade de Ciências Biológicas de Araras (FHO). Endereço eletrônico: crisvprado@gmail.com

** Advogado. Mestre e Doutor em Direito pela Pontifícia Universidade Católica de São Paulo. Idealizador e fundador de Cadernos de Direito e da Revista Discente Interinstitucional. Fundador e ex-Coordenador do Programa de Pós-Graduação em Direito da UNIMEP. Coordenador do NEDAEPI. Endereço eletrônico: vhtejerina@yahoo.com.br
} 


\section{INTRODUÇÃOO}

A saúde integra o rol dos direitos fundamentais expressos pela Constituição Federal de 1988 (CF/88). Sendo a saúde direito de todos e dever do Estado, este deve prover as condições indispensáveis ao seu pleno exercício mediante políticas sociais e econômicas e ao acesso universal e igualitário.

Os medicamentos constituem-se em um dos principais arsenais terapêuticos disponíveis para a promoção da saúde. Possuem um alto valor social que os diferenciam de qualquer outro produto, podendo assim serem considerados como bens públicos.

Apesar de sua importância, o Brasil tem sofrido com o desabastecimento no mercado, notadamente de alguns medicamentos mais antigos e de baixo custo, alguns dos quais considerados essenciais e sem substitutos, motivado principalmente por questões comerciais.

Insta lembrar que, conforme a CF/88, a saúde é dever do Estado, porém, o dever do Estado não exclui o dever das empresas. Ademais, a Organização das Nações Unidas (ONU), ao estabelecer os Objetivos de Desenvolvimento do Milênio, destaca no oitavo objetivo a necessidade de se estabelecer parcerias para o desenvolvimento, e nesse sentido, o acesso aos medicamentos essenciais deve ser promovido em cooperação com a indústria farmacêutica.

A Agência Nacional de Vigilância Sanitária (ANVISA) não dispõe de meios para obrigar o fabricante a continuar produzindo determinado medicamento. Entretanto, devido à sua essencialidade, é mister que o Estado crie mecanismos que garantam o pleno acesso da população. Nesse sentido, o presente trabalho tem como objetivo analisar a violação ao direito fundamental à saúde através da descontinuidade de produção de medicamentos mais antigos e baratos pela indústria farmacêutica, além de identificar possíveis mecanismos de resolução.

Para tanto, é feita uma análise das medidas tomadas pela agência reguladora argentina, a Administración Nacional de Medicamentos, Alimentos y Tecnología Médica (ANMAT), para evitar o desabastecimento do mercado local. Além disso, a partir da Lei de Inovação, é verificada a possibilidade de parcerias entre Poder Público e Organizações da Sociedade Civil de Interesse Público (OSCIPs), Instituições Científicas e Tecnológicas (ICTs) e empresas privadas, de forma a alcançar um desenvolvimento da inovação no país na área farmacêutica.

O trabalho sugere que, medidas simples, como as adotadas pela ANMAT, possam servir de inspiração para a elaboração de medidas no território nacional de forma a garantir o direito 
à saúde. Além disso, nos termos da Lei de Inovação, o fornecimento de medicamentos, o incentivo à pesquisa, à produção e à inovação na área farmacêutica poderia se tornar uma realidade a partir das parcerias anteriormente citadas.

Este artigo está organizado em três partes, além desta introdução. Na primeira parte serão feitas algumas reflexões sobre o direito à saúde. Além disso, serão discutidos os Objetivos de Desenvolvimento do Milênio e os Objetivos do Desenvolvimento Sustentável, mostrando que o acesso aos medicamentos seguros, eficazes e de baixo custo é uma preocupação mundial e que deve ser provido em parceria com a indústria farmacêutica.

Na segunda parte, serão tecidas algumas ponderações sobre os medicamentos como bens públicos. Logo após, verificar-se-á a descontinuidade de produção de medicamentos pela indústria farmacêutica. Em seguida, serão apresentadas as medidas tomadas pela ANMAT para evitar o desabastecimento do mercado de medicamentos argentino. Por fim, serão tecidas as considerações finais.

A proposta do presente trabalho é a de desenvolver uma investigação científica descritiva e analítica, com base na legislação nacional e estrangeira, além da doutrina e de artigos científicos relevantes acerca da temática.

\section{ALGUMAS CONSIDERAÇÕES SOBRE O INTERESSE PÚBLICO}

Inicialmente faz-se necessário traçar algumas considerações sobre o interesse público. A expressão "interesse público"1 nos remete habitualmente a uma categoria contraposta ao interesse privado, individual, isto é, ao interesse pessoal de cada um. Constitui-se no interesse do todo, ou seja, do próprio conjunto social, e não se confunde com a somatória dos interesses individuais. (MELLO, 2007, p. 56-57). Assim resume Calera a respeito:

A pesar de los debates sobre su naturaleza, nadie discute que el concepto de interés público recoge en cierta medida la tradición iusnaturalista del bien común y la tradición republicana de la voluntad general y constituye uno de esos conceptos-clave de las ciencias sociales. El interés público pretende significar un compendio de los fines prevalentes de un orden jurídico y político Los grandes objetivos del Estado y de la legislación giran fundamentalmente en torno al interés público.( 2010, p. 129).

\footnotetext{
1 Será sempre difícil elaborar uma teoria do interesse público, conceito geral indeterminado sujeito a "confusão" e "manipulação". No Código Civil de 2002 há vários exemplos: "perigo iminente" do art. 188; "urgência" do art. 251, § único; "necessidade imprevista e urgente" do art. 581; "risco" do art. 927, § único; "interesse público" do art. 1.278 "coisas necessárias" do art. 1.643, I; "divisão cômoda" do art. 2.019. Do ponto de vista da finalidade e da eficácia, os conceitos gerais indeterminados, uma vez diagnosticados pelo juiz no caso concreto, tem uma solução preestabelecida na lei, cabendo a ele aplicar a referida solução.
} 
O interesse público só se justifica na medida em que se constitui em veículo de realização dos interesses das partes que o integram no presente e das que o integrarão no futuro; é o interesse resultante do conjunto dos interesses que os indivíduos pessoalmente têm quando considerados em sua qualidade de membros da sociedade. (MELLO, 2007, p.59).

O interesse público é o núcleo dos princípios que norteiam a atividade administrativa, quais sejam, o princípio da supremacia do interesse público sobre o privado e o princípio da indisponibilidade do interesse público.

\subsection{Princípios basilares do Direito Administrativo}

O estudo dos princípios que norteiam qualquer ramo do Direito é imprescindível para a compreensão de sua lógica. Os princípios são os alicerces da ciência; suas proposições básicas, que condicionam todas as estruturações subseqüentes. (DI PIETRO, 2013, p. 63).

No âmbito do Direito Administrativo, o estudo dos princípios refere-se ao estudo do denominado regime jurídico administrativo. O regime jurídico administrativo é o "conjunto de traços, de conotações, que tipificam o Direito Administrativo, colocando a Administração Pública numa posição privilegiada, vertical, na relação jurídico-administrativa". Em linhas gerais, resume-se ao binômio prerrogativas e sujeições. (DI PIETRO, 2013, p. 61).

As prerrogativas são "as regalias usufruídas pela Administração, na relação jurídicoadministrativa, derrogando o direito comum diante do administrador"; são faculdades especiais das quais a Administração Pública pode fazer uso em face do particular. Já as sujeições ou restrições, obrigam a Administração a observar suas finalidades e princípios, sob pena de nulidade de seus atos. A Administração Pública, diferente dos particulares, só pode agir em conformidade com a lei e com o Direito. Algumas prerrogativas e sujeições a que se submete a Administração Pública são expressas sob a forma de princípios que informam o direito público, notadamente o Direito Administrativo. (DI PIETRO, 2013, p. 62-63).

De todos os princípios que norteiam a atividade administrativa, dois deles caracterizam o regime jurídico administrativo, notadamente, o princípio da supremacia do interesse público e o princípio da indisponibilidade do interesse público.

\subsubsection{Princípio da supremacia do interesse público}

Pelo princípio da supremacia do interesse público, em casos de confronto entre um interesse privado e um coletivo, deverá haver prevalência do interesse coletivo. Isto não implica 
necessariamente na total inobservância ao interesse privado. Existem limitações decorrentes do próprio sistema normativo, como por exemplo, o fato da atuação estatal estar adstrita ao principio da legalidade, ao respeito ao direito adquirido, ao ato jurídico perfeito e a coisa julgada, conforme o art. $5^{\circ}$, inc. XXXVI da $\mathrm{CF} / 88$. Afirma Calera que:

El interés público es un concepto y un valor recurrente en la legislación, en la jurisprudencia y en las acciones de gobierno en todos los niveles, un concepto y valor del que se echa mano para resolver conflictos o para justificar actuaciones de especial entidad en la vida jurídica y política. Ante el interés público ha de ceder cualquier otro interés. "Fiat 'interés público' et pereat mundus". (2010, p. 124).

O princípio da supremacia do interesse público é pressuposto de uma ordem social estável, em que todos e cada um possam sentir-se garantidos e resguardados. Por este princípio, o Poder Público se encontra em situação de autoridade, de comando, relativamente aos particulares, como indispensável condição para gerir os interesses públicos postos em confronto. (MELLO, 2007, p. 66-67).

Importante ressaltar que a Administração Pública exerce uma função: a função administrativa. Existe função quando alguém está investido no dever de satisfazer dadas finalidades em prol do interesse de outrem, necessitando para tanto, manejar os poderes em prol destes interesses, a fim de que tais finalidades sejam alcançadas. Tais poderes são, na verdade, instrumentos para o alcance das sobreditas finalidades. Ademais, seu titular maneja "deverespoderes", no interesse alheio, o que legitima o uso das prerrogativas pela Administração, quando e na medida indispensável ao atendimento dos interesses públicos. (MELLO, 2007, p. 68-69).

\subsubsection{Princípio da indisponibilidade do interesse público}

O princípio da indisponibilidade do interesse público indica que, como os interesses são inerentes à coletividade, estes não estão à livre disposição do administrador e nem do próprio órgão administrativo que os representa. (MELLO, 2007, p. 70). O titular do interesse público é o Estado, que por sua vez, tem o dever de concretizá-lo nos limites de sua finalidade e da ordem jurídica a ele aplicada.

Dos princípios da supremacia do interesse público sobre o privado e da indisponibilidade do interesse público decorre o regime jurídico administrativo brasileiro. 


\section{DIREITO À SAUDE}

A Organização Mundial da Saúde (OMS), fundada em 1948, é um organismo sanitário internacional integrante da ONU. O conceito de saúde segundo a OMS pode ser entendido como um "estado de completo bem-estar físico, mental e social, e não somente a ausência de enfermidade ou invalidez". (SÁ JUNIOR, 2004, p.15).

A saúde é um direito previsto constitucionalmente, e está inserida no rol dos direitos sociais, conforme dicção do art. $6^{\circ}$ da $\mathrm{CF} / 88$. Ademais, o art. 196 da $\mathrm{CF} / 88$ estabelece ainda que a saúde é direito de todos e dever do Estado, garantido mediante políticas sociais e econômicas e ao acesso universal e igualitário.

Em nível infraconstitucional, a Lei № 8.080, de 19 de setembro de 1990, conhecida como Lei Orgânica da Saúde, estabelece que a saúde é um direito fundamental do ser humano, e que o Estado deve prover as condições indispensáveis ao seu pleno exercício através da formulação e execução de políticas econômicas e sociais. Além disso, determina que o dever do Estado em relação à garantia da saúde não exclui o dever das empresas.

\subsection{Os Objetivos de Desenvolvimento do Milênio}

Os Objetivos de Desenvolvimento do Milênio foram formulados a partir da Declaração do Milênio da ONU em setembro de 2000, com o apoio de 191 nações. Através da Declaração, os países membros se comprometeram com uma série de compromissos voltados para áreas prioritárias como educação e saúde. Os objetivos são descritos abaixo:

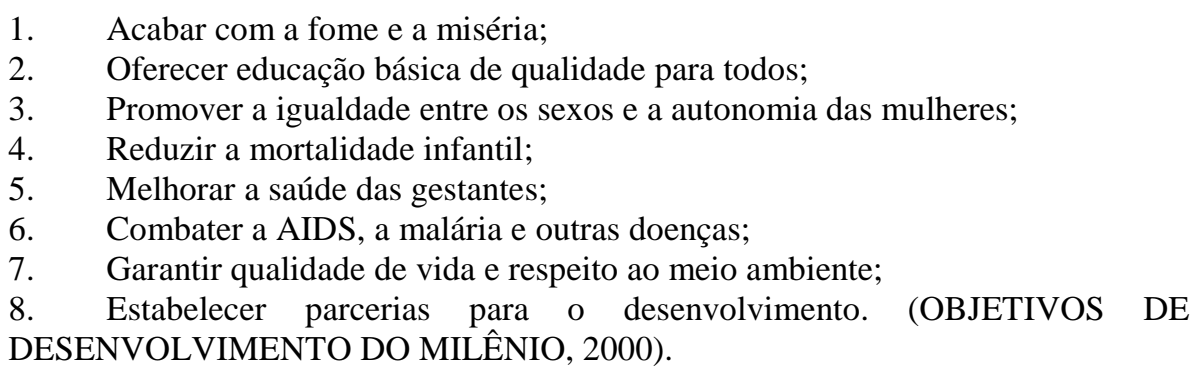

A ONU acrescenta ao oitavo objetivo, ou seja, estabelecer parcerias para o desenvolvimento, que o acesso a medicamentos essenciais aos países em desenvolvimento deve ser provido em cooperação com a indústria farmacêutica. (ZANIN NETO, 2010, p.25). 


\subsection{Os Objetivos de Desenvolvimento Sustentável}

Devido aos resultados promissores obtidos com os Objetivos de Desenvolvimento do Milênio, a Assembleia Geral da ONU adotou um novo plano de ação, intitulado Objetivos do Desenvolvimento Sustentável, os quais deverão ser alcançados até o ano de 2030.

Essa nova agenda foi lançada durante a Cúpula de Desenvolvimento Sustentável e reflete os novos desafios a serem enfrentados pelas nações. Possui 17 objetivos e 169 metas que buscam concretizar os direitos humanos. Os objetivos são definidos a seguir.

1. Acabar com a pobreza em todas as suas formas, em todos os lugares;

2. Acabar com a fome, alcançar a segurança alimentar e melhoria da nutrição e promover a agricultura sustentável;

3. Assegurar uma vida saudável e promover o bem-estar para todos, em todas as idades;

4. Assegurar a educação inclusiva e equitativa e de qualidade, e promover oportunidades de aprendizagem ao longo da vida para todos;

5. Alcançar a igualdade de gênero e empoderar todas as mulheres e meninas;

6. Assegurar a disponibilidade e gestão sustentável da água e saneamento para todos;

7. Assegurar o acesso confiável, sustentável, moderno e a preço acessível à energia para todos;

8. Promover o crescimento econômico sustentado, inclusivo e sustentável, emprego pleno e produtivo e trabalho decente para todos;

9. Construir infraestruturas resilientes, promover a industrialização inclusiva e sustentável e fomentar a inovação;

10. Reduzir a desigualdade dentro dos países e entre eles;

11. Tornar as cidades e os assentamentos humanos inclusivos, seguros, resilientes e sustentáveis;

12. Assegurar padrões de produção e de consumo sustentáveis;

13. Tomar medidas urgentes para combater a mudança do clima e seus impactos;

14. Conservação e uso sustentável dos oceanos, dos mares e dos recursos marinhos para o desenvolvimento sustentável;

15. Proteger, recuperar e promover o uso sustentável dos ecossistemas terrestres, gerir de forma sustentável as florestas, combater a desertificação, deter e reverter a degradação da terra e deter a perda de biodiversidade;

16. Promover sociedades pacíficas e inclusivas para o desenvolvimento sustentável, proporcionar o acesso à justiça para todos e construir instituições eficazes, responsáveis e inclusivas em todos os níveis;

17. Fortalecer os meios de implementação e revitalizar a parceria global para o desenvolvimento sustentável. (ORGANIZAÇÃO DAS NAÇÕES UNIDAS, 2015).

Com o intuito de se alcançar o terceiro objetivo, ou seja, assegurar uma vida saudável e promover o bem-estar para todos, em todas as idades, deve-se buscar o acesso a medicamentos e vacinas essenciais, que sejam seguros, eficazes, de qualidade e que tenham preços acessíveis para todos. 


\section{A QUESTÃO DA DESCONTINUIDADE DE MEDICAMENTOS}

Uma das características inerentes à atividade empresarial é a atividade econômica organizada. Esta pressupõe que a empresa é uma atividade de produção ou circulação de bens ou serviços. A empresa, sendo atividade, não se confunde com o sujeito de direito que o explora, o empresário. Além disso, a atividade empresarial é econômica, pois tem como objetivo a busca de lucro, e é organizada pelo fato de que o empresário articula os fatores de produção, a saber, o capital, a mão-de-obra, os insumos e a tecnologia empregada. (COELHO, 2013, p. 32).

No tocante à indústria farmacêutica não é diferente. Como qualquer outro setor empresarial, a indústria farmacêutica, "enquanto atividade habitual e organizada dotada de conteúdo econômico e de intuito lucrativo é exercida mediante o risco inerente a toda atividade econômica". (VIZZOTTO, 2010, p. 270). Neste sentido, não é difícil concluir que a assunção de tais riscos só se justifica mediante a possibilidade da aferição de lucro.

Assim, relativamente ao processo de desenvolvimento de novos medicamentos até a sua colocação no mercado, alegam as indústrias farmacêuticas que este envolve operações de elevado nível de incerteza e de complexidade. A chegada de um medicamento ao mercado leva em média 7 a 10 anos e exige vultosos investimentos financeiros. (MONEDERO, 2002, p.196). Desta forma, os laboratórios voltam seus esforços para nichos de mercado, isto é, para aquelas doenças, agravos ou parcelas da população que representam um público consumidor e gerador de lucro. (CARVALHO, 2016, p. 2).

Neste sentido, algumas indústrias interrompem a produção de determinados medicamentos, inclusive alguns considerados essenciais e sem substitutos, que embora estejam há anos no mercado e apresentem eficácia comprovada, já não trazem o mesmo lucro do período de exploração exclusiva da patente. Conforme relatório final da Comissão Parlamentar de Inquérito (CPI) dos Medicamentos, "a visão dominante no campo da produção farmacêutica divorciou-se profunda e gravemente da ótica sanitária". (CÂMARA DOS DEPUTADOS, 2000, p. 134).

Um estudo da Organização Pan-Americana da Saúde (OPAS) em parceria com a OMS denunciou o desinteresse por parte das indústrias farmacêuticas em manter a comercialização destes medicamentos. $\mathrm{O}$ estudo traz exemplos de vários medicamentos que foram descontinuados, dentre eles destacam-se a $L$ - asparaginase (indicada para o tratamento de leucemia linfócita aguda em pacientes pediátricos); a fenitoína (indicada como 
anticonvulsivante), além de alguns grupos de insumos farmacêuticos ativos como antibióticos e produtos usados no tratamento de doenças raras, mas que possuem um número reduzido de pacientes consumidores. (REZENDE, 2016, p. 2).

Isso se torna mais visível quando da renovação do registro sanitário exigido pela ANVISA. A lei que trata do registro sanitário é a Lei № 6.360, de 23 de setembro de 1976. Em seu art. 16 dispõe que o registro de drogas, medicamentos, insumos farmacêuticos e correlatos, dadas as suas características sanitárias, medicamentosas ou profiláticas, curativas, paliativas, ou mesmo para fins de diagnóstico, fica sujeito, além do atendimento das exigências próprias, a uma série de requisitos específicos, dentre eles, a comprovação científica e de análise, que seja reconhecido como seguro e eficaz para o uso a que se propõe e possua a identidade, atividade, qualidade, pureza e inocuidade necessárias. No entanto, alegam as empresas farmacêuticas que o atendimento a tais exigências envolvem custos altíssimos, que por sua vez inviabilizam a continuidade da produção, e com isso informam sua intenção de interromper a produção destes produtos. (REZENDE, 2016, p. 2).

Os laboratórios buscam investir em novos produtos, muitas vezes, cópias "maquiadas" dos originais através das quais os preços são aumentados. (CÂMARA DOS DEPUTADOS, 2000, p. 112). Nesse sentido, afirma o Departamento de Saúde da Inglaterra, que a pesquisa no setor farmacêutico está voltada para os lucros comerciais ao invés de atender às necessidades terapêuticas. (MELO; RIBEIRO; STORPIRTIS, 2006, p. 477).

Em 2017, o jornal Folha de São Paulo também denunciou a descontinuidade de medicamentos antigos e de baixo custo, alguns deles considerados essenciais e sem substitutos, devido à falta de interesse comercial pelos laboratórios farmacêuticos. Segundo a reportagem, muitas das drogas descontinuadas são utilizadas no tratamento do câncer, e os pacientes que dependem destas drogas sofrem sérias conseqüências, pois, os novos antineoplásicos, na grande maioria, não possuem a mesma eficácia no tratamento, ou não são viáveis economicamente. Um exemplo disso é o melfalano, droga usada no tratamento do mieloma múltiplo e essencial no transplante de medula, que teve a produção interrompida temporariamente em 2017. (COLLUCCI; HERNANDES, 2017).

Consoante a ANVISA, a falta de um medicamento no mercado causada por interrupção na produção, seja de forma temporária ou definitiva, decorre de diversos fatores, dentre eles o aumento na demanda, a motivação comercial, questões logísticas, problemas relativos ao 
parque fabril, ao processo de fabricação e ao princípio ativo. (AGÊNCIA NACIONAL DE VIGILÂNCIA SANITÁRIA, 2018).

Segundo a Resolução da Diretoria Colegiada № 18, de 04 de abril de 2014 (RDC № 18/2014), considera-se descontinuação temporária os casos de suspensão temporária da fabricação ou importação de medicamentos, em que não haja a intenção do titular de cancelar ou não requerer a renovação do registro do produto. Já a descontinuação definitiva se refere aos casos em que haja a intenção do titular de cancelar ou não requerer a renovação do registro do produto.

A RDC № 18/2014 determina ainda que a comunicação à ANVISA da descontinuação temporária ou definitiva da fabricação ou importação de medicamentos deverá ser realizada com, no mínimo, 180 dias de antecedência da data de sua implementação. Já no caso de descontinuação temporária ou definitiva da fabricação ou importação de medicamentos que possam causar desabastecimento no mercado, a comunicação à ANVISA deverá ocorrer com 12 meses de antecedência. Ademais, nos casos de descontinuação não-programada da fabricação ou importação de medicamentos decorrente de fato imprevisto, que impactem sua qualidade, segurança ou eficácia, e que possam causar desabastecimento de mercado, a comunicação à ANVISA deverá ocorrer no prazo máximo de 72h da ciência do problema.

Verifica-se no site da ANVISA que 2.366 drogas tiveram sua produção interrompida no período de 01 de abril de 2014 até 14 de abril de 2018. Desse montante, 63,86\% foram decorrentes de motivação comercial (de forma definitiva e temporária) e os 36,13\% restantes foram causados pelos demais motivos. Além disso, ainda pode-se constatar que, do total das drogas pesquisadas, apenas $21,04 \%$ tiveram sua produção reativada. Portanto, a motivação comercial é o principal fator a determinar a descontinuidade na produção desses medicamentos. (AGÊNCIA NACIONAL DE VIGILÂNCIA SANITÁRIA, 2018b).

A ANVISA possui competência para atuar monitorando casos críticos em que a descontinuação pode causar desabastecimento no mercado. Ademais, pode dar publicidade aos medicamentos que terão sua fabricação interrompida, autorizar a importação excepcional para suprir o mercado e priorizar a análise de medicamentos que possam suprir o mercado. (AGÊNCIA NACIONAL DE VIGILÂNCIA SANITÁRIA, 2018a). Todavia, quando o medicamento não está sob o manto da proteção patentária, a ANVISA não possui qualquer instrumento legal que obrigue o fabricante a manter a produção de certos medicamentos ou que 
o impeça de retirá-los do mercado, mesmo que sejam considerados essenciais. Apenas durante o período de vigência da patente, a Lei de Propriedade Industrial prevê o mecanismo da licença compulsória em casos de emergência nacional ou interesse público ${ }^{2}$.

Em obra ainda inédita sobre Contratos de Propriedade Intelectual (em fase de elaboração) ${ }^{3}$, de acordo com o oitavo objetivo das Metas do Milênio da ONU, qual seja, estabelecer parcerias para o desenvolvimento, especialmente prover o acesso a medicamentos essenciais aos países em desenvolvimento em cooperação com a indústria farmacêutica, antes referido, bem se poderia, nos termos da Lei de Inovação ${ }^{4}$, estabelecer acordos de parceria entre o Poder Público e as entidades qualificadas como OSCIPs, as ICTs e as empresas privadas nacionais. Assim, a Lei da Inovação abre espaço para que empresas privadas, representando o mercado, possam se unir às Universidades Públicas, representantes da maior parte da produção de pesquisas, buscando o desenvolvimento de inovação no país, especialmente em uma das áreas mais importantes para o Brasil, como a produção de medicamentos essenciais.

Ademais, o acordo de parceria também poderia contemplar redes e projetos internacionais de pesquisa tecnológica, bem como ações de empreendedorismo tecnológico e de criação de ambientes de inovação, inclusive incubadora e parques tecnológicos destinados a produção de medicamentos considerados essenciais para o país o que, a médio e longo prazo, resultaria na formação de grandes empresas farmacêuticas de capital nacional comprometidas em atender o direito à saúde e certamente lucrar, pois se trata de um mercado promissor e seguro.

Os laboratórios alegam que a defasagem de preços decorrente da política governamental é a principal responsável pelo desabastecimento de medicamentos, pois, os preços autorizados não seriam suficientes para cobrir os custos de produção. Em resposta, o Ministério da Saúde diz estar revisando os preços aplicados, notadamente daqueles medicamentos que não possuem substitutos. (COLLUCCI; HERNANDES, 2017).

Ao longo da história, o Brasil já enfrentou problemas com a falta de oferta de medicamentos. Conforme consta do relatório final da CPI dos Medicamentos sobre a experiência brasileira no controle de preços de medicamentos, nas décadas de 1970/80, quando os preços eram controlados pelo antigo Conselho Interministerial de Preços (CIP), o mercado

\footnotetext{
${ }^{2}$ Vide art. 71 da Lei № 9.279/96.

${ }^{3}$ Contratos de Propriedade Intelectual, de autoria de Victor Hugo Tejerina Velázquez e Armando Zanin Neto.

${ }^{4}$ Lei № 10.973, de 2 de dezembro de 2004, alterada pela Lei № 13.243, de 11 de janeiro de 2016.
} 
de medicamentos também sofreu com o desabastecimento. A política de preços da época se mostrou desastrosa, e os laboratórios interromperam o fornecimento de vários medicamentos alegando insuficiência de margem de lucro. (CÂMARA DOS DEPUTADOS, 2000, p. 107).

O controle de preços, tal qual aplicado no respectivo período se mostrou ineficaz, pois, os laboratórios deixavam de produzir ou lançavam novos medicamentos, na maioria das vezes, cópias disfarçadas dos medicamentos antigos, mas que serviam como artifício para aumentarem os preços. (CÂMARA DOS DEPUTADOS, 2000, p. 112).

Por outro lado, quanto à suposta insuficiência dos preços dos medicamentos, na CPI dos Medicamentos realizada de novembro de 1999 a maio de 2000 já se denunciava que alguns medicamentos tiveram aumento de mais de $200 \%$, conforme se verifica a seguir:

\begin{abstract}
Convidado pela CPI para depor em nome da Federação Nacional dos Médicos (Fenam), Heder Murari Borba, afirmou na mesma sessão que há medicamentos "que tiveram mais de $200 \%$ de reajuste", acrescentando que "está clara a incapacidade do governo em controlar tais abusos". E perguntou: "Será incapacidade de fiscalização ou conluio com os grandes grupos econômicos que representam a indústria farmacêutica?". Além disso, o presidente da Fenam anunciou aos membros da CPI a deflagração de uma ampla campanha nacional junto às entidades médicas regionais, para denunciar os abusos da indústria farmacêutica no Brasil e a incapacidade de resposta do governo federal. O debate da questão dos medicamentos e a investigação dos abusos cometidos por várias indústrias do país têm tomando corpo depois de mais de uma década de absoluto descaso do governo para com as atividades do setor. Essa liberdade irresponsável concedida aos fabricantes de medicamentos praticamente fechou as portas das farmácias do país a uma larga faixa de baixa e média renda da população. (PORTAL MÉDICO, 2000).
\end{abstract}

Contudo, "é urgente a necessidade de se construir um ambiente de regulação de preços que possa superar os problemas decorrentes das falhas de mercado". (CÂMARA DOS DEPUTADOS, 2000, p. 116). E ainda, o Estado deve assumir a produção destes medicamentos de forma direta, por exemplo, fortalecendo os laboratórios oficiais. (CÂMARA DOS DEPUTADOS, 2000, p. 133).

Nesse sentido, seria uma grande oportunidade para estabelecer, nos termos da Lei de Inovação, acordos de parceria que atendam necessidades fundamentais como o fornecimento de medicamentos e incentivem a pesquisa, a produção farmacêutica e a inovação.

\title{
3.1 Medicamentos são produtos comuns?
}

O uso de medicamentos influenciou de modo decisivo a composição demográfica das populações, com reflexos de ordem política, econômica e social. Desta forma, os medicamentos exigem um tratamento singular, afinal, possui a finalidade de preservar o direito fundamental à 
saúde. (SATO, 2002, p. 90). “Os medicamentos são um bem público e não apenas outra mercadoria; em primeiro lugar devido a seu alto valor social e também, porque consumidores e prescritores não têm acesso a sua qualidade, segurança e eficácia”. (MINISTÉRIO DA SAÚDE; AGÊNCIA NACIONAL DE VIGILÂNCIA SANITÁRIA; ORGANIZAÇÃO PANAMERICANA DA SAÚDE/ORGANIZAÇÃO MUNDIAL DA SAÚDE, 2005, p. 65).

Pode-se afirmar que medicamentos possuem peculiaridades tais que exigem uma atenção especial, notadamente por parte da legislação sanitária, no sentido de minimizar os riscos que envolvem sua utilização. Além disso, é necessária uma consciência jurídica sobre a necessidade de disciplinar toda sua cadeia de produção e venda, que por sua finalidade, possui considerável caráter público. (PIANETTI, 2016, p. 2).

Os medicamentos constituem-se em um dos principais arsenais terapêuticos disponíveis para a promoção da saúde e com isso adquirem relevância pública. Sua natureza especial decorre, dentre outros fatores, da baixa relação elasticidade-preço no que se refere à sua demanda. Por serem considerados essenciais, seu consumo independe dos preços. "O medicamento é uma mercadoria muito específica, um objeto entre a ciência, o mercado e a sociedade". (CÂMARA DOS DEPUTADOS, 2000, p. 212-214).

Parece pertinente recordar que, ao indagar os fundamentos do Direito é essencial conduzir à descoberta do profundo senso ético que se precisa ter como condição necessária para preservar o Estado de Direito, especialmente quando se percorre o vasto universo do Direito e quando se reflete sobre um direito fundamental, qual seja, o direito à saúde. Embora não da direção da relação complementar a que Habermas aderiu entre moral e Direito seguindo a linha traçadas nas Tanner Lectures (aulas ministradas entre 1986-87 na Harvard University) e que mais tarde rejeitou (HABERMAS, 1997, p. 10), mas no sentido em que as reflexões jurídicas deveriam ser permeadas pela ética porque as "questões ético-políticas colocam-se na perspectiva de membros que procuram obter clareza sobre a forma de vida que estão compartilhando e sobre os ideais que orientam seus projetos comuns de vida". (HABERMAS, 1997, p. 201).

A complexidade quanto aos medicamentos não diz respeito apenas à fase de pesquisa e desenvolvimento. E exatamente por esta razão, toda a cadeia é regulamentada: a pesquisa, a produção pelos laboratórios, a distribuição pelos atacadistas e a dispensação pelas farmácias e drogarias. Ademais, para que a população tenha um maior acesso aos medicamentos, dada a 
sua complexidade, é necessário uma articulação inter-setorial. A esse respeito, os comentários de Paula et al. merecem transcrição literal:

Observa-se que todas as iniciativas tomadas no sentido de garantir maior promoção, proteção e recuperação da saúde, individual e coletiva, tendo o medicamento como foco, envolvem uma complicada articulação entre setores, que inclui desde a pesquisa/desenvolvimento/produção, bem como as etapas relacionadas à garantia de que a população terá acesso a um produto (medicamento) de qualidade, em quantidade suficiente, sob orientação profissional competente, capaz de assegurar seu uso racional. (PAULA; ALVES; VIEIRA; SOUZA, 2009, p. 1115).

\section{Conforme destaca o relatório final da CPI dos medicamentos, algumas características}

tornam o medicamento um produto extremamente peculiar:

a) somente é (ou deveria ser) autorizado a entrar no mercado para uma ou mais indicações, precisas, testadas em longas pesquisas clínicas pelo produtor, que deve listar todas as propriedades, positivas e negativas, do produto. Usado fora da indicação e da forma e dose em que foi testada sua relevância terapêutica, um medicamento causa seguramente mais prejuízo do que benefícios ao seu usuário;

b) às vezes, tem a dose terapêutica muito próxima da dose tóxica, ou seja, a relação eficácia/segurança é crítica para a terapêutica e depende de avaliação de pessoal qualificado, em cada caso, e de orientação correta ao paciente ou consumidor;

c) a oferta e a procura do medicamento não estão relacionadas, como no caso de outras mercadorias, à vontade ou ao desejo do sujeito, nem mesmo depende só da sua capacidade aquisitiva em obtê-lo. Antes, depende de uma necessidade objetiva, manifestada em determinado momento da vida do indivíduo. As doenças têm estreita relação com a situação social de uma comunidade e têm seus determinantes ligados a variáveis epidemiológicas de cunho biológico, social, cultural e econômico;

d) tem uma importância crítica para a segurança social; é objeto de utilidade pública e função social peculiares; em muitos casos, é a diferença entre a vida e a morte; é insumo de programas relacionados às funções do Estado;

e) tem o seu acesso restringido a indicações específicas; não pode ter seu consumo induzido ou estimulado; seu uso é principalmente realizado em situações de fragilidade de consciência e do organismo dos pacientes;

f) seu consumo deve ser racional, ou seja, restrito às doses e formas de uso recomendadas, nas situações indicadas, na medida necessária; caso contrário, seus efeitos gerarão outros problemas, além dos já existentes, constituindo círculos viciosos de problemas de saúde iatrogênicos (como bem exemplificou nesta CPI o exDeputado Elias Murad) que já são responsáveis por cerca de $10 \%$ das internações ou de seus prolongamentos;

g) tem suas especificações de qualidade, eficácia e segurança reguladas e monitoradas de forma rigorosa, não se permitindo falhas ou gradação em sua qualidade. (CÂMARA DOS DEPUTADOS, 2000, p. 212).

Quando se trata de acesso à saúde e, sobretudo, de acesso aos medicamentos, o tema central do debate, segundo as Nações Unidas, é saber qual o efeito das normas de propriedade intelectual, de modo particular das patentes e dos direitos do autor, sobre a capacidade que têm os Estados para cumprir com as obrigações contraídas em virtude da normativa internacional 
de direitos humanos, como a obrigação de garantir o acesso a medicamentos acessíveis ${ }^{5}$, a uma ${\text { alimentação } \text { adequada }^{6} \text { e ao material educativo }}^{7}$. (NACIONES UNIDAS, 2005).

O uso racional de medicamentos, segundo a OMS, ocorre quando pacientes recebem medicamentos apropriados para suas condições clínicas, em doses adequadas às suas necessidades individuais, por um período adequado e ao menor custo para si e para a comunidade. (WORLD HEALTH ORGANIZATION, 1985). Tratamentos como o do câncer, por exemplo, não podem sofrer interrupções. A falta de um medicamento essencial, mesmo que temporariamente, pode acelerar o crescimento das células tumorais e reduzir significativamente as chances de cura.

Há um desafio importante no sentido de evitar o desabastecimento do mercado de tais medicamentos, desafio este que exige um esforço tanto do Poder Público como do setor privado. No entanto, como se verá adiante, medidas relativamente simples poderiam evitar que os pacientes ficassem sem tratamento. O Poder Público, diante do interesse público existente na manutenção destes medicamentos no mercado, precisa agir de modo a incentivar as indústrias que pretendam dar continuidade na sua produção e, não menos importante, precisa rever o processo de obtenção do registro sanitário.

\section{A EXPERIÊNCIA ARGENTINA}

A agência reguladora argentina, a ANMAT, foi criada pelo Decreto № 1.490 de 1992, é ligada ao Ministério da Saúde e é a responsável pelo controle sanitário nacional. Dentre as suas competências estão o controle sanitário e de qualidade de drogas, produtos químicos, reativos, fórmulas farmacêuticas, medicamentos, elementos de diagnóstico, materiais e tecnologias biomédicas e de qualquer produto de uso e aplicação em medicina humana. Ademais, também possui responsabilidade sobre a vigilância da eficácia e detecção dos efeitos adversos que resultem do consumo e utilização destes produtos, além do controle de processos,

\footnotetext{
${ }^{5} \mathrm{O}$ direito à saúde está consagrado no art. 12 do Pacto Internacional de Direitos Econômicos, Sociais e Culturais e no art. 24 da Convenção sobre os Direitos da Criança. Do mesmo modo se interpreta na Observação Geral № 14 (2000) do Comitê de Direitos Econômicos, Sociais e Culturais e na Observação Geral № 3 (2003) sobre HIV/SIDA e os Direitos da Criança, e na Observação Geral № 4 (2003) sobre a saúde e o desenvolvimento dos adolescentes, do Comitê dos Direitos da Criança. (tradução nossa).

${ }^{6} \mathrm{O}$ direito à alimentação está consagrado no art. 11 do Pacto Internacional de Direitos Econômicos, Sociais e Culturais e no art. 27 da Convenção sobre os Direitos da Criança. Do mesmo modo se examina na Observação Geral № 12 (1999) do Pacto Internacional de Direitos Econômicos, Sociais e Culturais. (tradução nossa).

${ }^{7} \mathrm{O}$ direito à educação está consagrado no Art. 13 do Pacto Internacional de Direitos Econômicos, Sociais e Culturais e no Art. 28 da Convenção sobre os Direitos da Criança, do mesmo modo se interpreta na Observação Geral nº 13 (1999). (tradução nossa).
} 
atividades e tecnologias que se realizem em função do aprovisionamento, produção, elaboração, fracionamento, importação e/ou exportação, depósito e comercialização dos produtos relacionados. (MADIES, 2010, p. 126).

A ANMAT, de modo diverso da ANVISA, não realiza de forma integral a inspeção e controle do canal de distribuição de medicamentos, não é responsável pelo controle de preços, e também não participa do procedimento de concessão de patentes. (MADIES, 2010, p. 120).

Diante da possibilidade de desabastecimento de medicamentos no mercado argentino, a ANMAT editou a Disposición № 2.038, de 24 de fevereiro de 2017, estabelecendo medidas protetivas para a garantia da oferta de medicamentos no mercado local.

Segundo a Disposición № 2.038/2017, os titulares de certificados inscritos no Registro de Especialidades Medicinais (REM) que tenham caráter de comercializados deverão notificar à ANMAT todo fato de que tenham ciência que possa colocar em risco a oferta destes produtos, e consequentemente, provocar sua descontinuidade temporária ou definitiva. A notificação deverá ocorrer com uma antecedência mínima de 180 dias, e caso seja inviável, deverá ser feita dentro dos 5 dias posteriores ao conhecimento de circunstâncias relevantes que possam provocar o desabastecimento no mercado.

Para aqueles que decidam descontinuar de forma definitiva a elaboração e/ou a importação de um produto, sempre que exista um similar no mercado, a notificação deverá ser feita à ANMAT com uma antecedência mínima de 6 meses.

Ademais, todo laboratório titular de registro com vigência terapêutica que decida descontinuar de forma definitiva a elaboração e/ou importação e comercialização de uma especialidade médica sem razões sanitárias que a justifiquem e sempre que não haja uma especialidade médica similar e comercializada no país, deverá informar à ANMAT com antecedência de 6 meses da descontinuidade, além de assegurar o abastecimento da especialidade médica durante os 6 meses que antecedem à interrupção da elaboração, importação ou comercialização.

Em se tratando de descontinuidade definitiva, a ANMAT poderá tornar pública a situação e incentivar outros laboratórios públicos ou privados que possam ter interesse em solicitar uma autorização de comercialização deste medicamento, além de outras medidas adicionais que possam ser adotadas por questões de saúde pública. Até que o novo titular tenha condições de elaborar, importar e comercializar o produto ou que a autoridade sanitária tenha 
tomado medidas adicionais, o laboratório que notifica a descontinuidade deverá assegurar o abastecimento do mercado.

O não cumprimento de tais medidas pelos laboratórios enseja a aplicação de sanções estabelecidas na Ley № 16.463, de 23 de julho de 1964 (Ley de Medicamentos) e no Decreto № 341, de 24 de fevereiro de 1992 (que trata das sanções pecuniárias aplicáveis a infrações cometidas contra normas sanitárias), tais como aplicação de multa e cancelamento da autorização para fabricação e importação de medicamentos.

\section{CONSIDERAÇÕES FINAIS}

A saúde integra o rol dos direitos fundamentais expressos pela $\mathrm{CF} / 88$ e o Estado deve prover as condições indispensáveis ao seu pleno exercício mediante políticas sociais e econômicas e ao acesso universal e igualitário.

Os medicamentos representam um dos principais arsenais terapêuticos disponíveis para a promoção da saúde, pois, melhoram a qualidade de vida da população. Desta forma, devido ao interesse público envolvido e ao elevado valor social, que os tornam produtos peculiares, estes devem ser considerados como bem público.

No entanto, o mercado de medicamentos apresenta falhas, e uma delas é a interrupção no abastecimento de determinados medicamentos, alguns dos quais considerados essenciais e sem substitutos, motivada principalmente por questões comerciais.

A legislação brasileira prevê apenas a necessidade de notificação prévia para os casos em que o laboratório farmacêutico pretenda interromper a produção de um determinado medicamento, mas não possui qualquer mecanismo que obrigue o detentor do registro a continuar produzindo ou comercializando tal produto.

A experiência argentina nos mostra que há meios do Estado intervir para equilibrar o interesse público e o privado na saúde pública. A ANMAT, ao editar a Disposición № 2.038/2017, estabeleceu medidas protetivas para a garantia da oferta de medicamentos no mercado local. Segundo a Disposición, os laboratórios farmacêuticos são obrigados a manter o abastecimento do mercado até que outros laboratórios ou mesmo o Poder Público possam fazêlo, sob pena de sanções bastante rígidas. 
Ademais, nos termos da Lei de Inovação, seria pertinente o estabelecimento de acordos de parcerias entre o Poder Público e as entidades qualificadas como OSCIPs, as ICTs, e as empresas privadas nacionais, de forma a promover maior acesso aos medicamentos, além de buscar o desenvolvimento da inovação no país na área farmacêutica.

Para finalizar, de todo o exposto, conclui-se que, dada a complexidade que envolve a questão dos medicamentos, se faz necessário uma articulação entre os setores envolvidos, de forma a garantir um maior acesso da população a estes produtos, que, pela sua essencialidade, são indispensáveis à manutenção da vida.

\section{REFERÊNCIAS}

ADMINISTRACIÓN NACIONAL DE MEDICAMENTOS, ALIMENTOS Y TECNOLOGÍA MÉDICA. Disposición № 2038. Buenos Aires: ANMAT, 24 fev. 2017. Disponível em: <http://www.anmat.gob.ar/boletin_anmat/BO/Disposicion_2038-2017.pdf.> Acesso em: 05 mai. 2018.

AGÊNCIA NACIONAL DE VIGILÂNCIA SANITÁRIA. Por que não encontro meu medicamento no mercado. Brasília: ANVISA. Disponível em: <http://portal.anvisa.gov.br/descontinuacao-de-medicamentos>. Acesso em 14 abr. 2018a.

AGÊNCIA NACIONAL DE VIGILÂNCIA SANITÁRIA. Portal Analítico. Descontinuação de Medicamentos. Brasília: ANVISA.

Disponível em: < http://portalanalitico.anvisa.gov.br/descontinuacao-de-medicamentos>. Acesso em: 08 abr. 2018b.

CALERA, Nicolás López. El Interés Público: entre la Ideología y el Derecho. In: Anales de la Cátedra Francisco Suárez, v. 44, 2010. Disponível em: <revistaseug.ugr.es/index.php/acfs/article/download/502/592>. Acesso em 10 jun. 2018.

CÂMARA DOS DEPUTADOS. Relatório da CPI-Medicamentos. Relator: Deputado Ney Lopes. Brasília, 30 mai. 2000.20 Disponível <file:///C:/Users/cris/Pictures/cpimedic_relp.PDF>. Acesso em: 02 jun. 2018.

CARVALHO, Felipe Dias. PD\&I: o uso racional "nasce" antes do medicamento. Série Uso Racional de Medicamentos: fundamentação em condutas terapêuticas e nos macroprocessos da Assistência Farmacêutica. OPAS/OMS. Brasília, v.1, № 2, p.1-5, fevereiro $2016 . \quad$ Disponível em: <http://www.paho.org/bra/index.php?option=com_docman\&view=download\&category_slug 
=serie-uso-racional-medicamentos-284\&alias=1530-pd-i-o-uso-racional-nasce-antes-domedicamento-0\&Itemid=965>. Acesso em: 05 abr. 2018.

COELHO, Fábio Ulhoa. Manual de direito comercial: direito de empresa. 25 ed. São Paulo: Saraiva, 2013.

COLLUCCI, Cláudia. HERNANDES, Raphael. Baixos preços fazem empresas tirarem do mercado medicamentos essenciais. Folha de São Paulo, São Paulo, 08 jul. 2017. Cotidiano. Disponível em: <http://www1.folha.uol.com.br/cotidiano/2017/07/1899515-baixos-precos

fazem-empresas-tirarem-do-mercado-medicamentos-essenciais.shtml>. Acesso em: 19 abr. 2018 .

DI PIETRO, Maria Sylvia Zanella. Direito Administrativo. 26 ed. São Paulo: Atlas, 2013.

HABERMAS, Jürgen. Direito e Democracia. Entre facticidade e validade, vol. 1. Trad. Flávio Beno Sienbeneichler. Rio de Janeiro: Tempo Brasileiro, 1997.

MADIES, Claudia Viviana. A contribuição e desafios da Administração Nacional de Medicamentos, Alimentos e Tecnologia Médica - ANMAT - ao direito à saúde dos argentinos. Revista de Direito Sanitário, São Paulo, v. 10, n. 3, p. 115-151, fev. 2010.

MELlO, Celso Antônio Bandeira de. Curso de Direito Administrativo. 24 ed. São Paulo: Malheiros, 2007.

MELO, Daniela Oliveira de; RIBEIRO, Eliane; STORPIRTIS, Sílvia. A importância e a história dos estudos de utilização de medicamentos. Revista Brasileira de Ciências Farmacêuticas, São Paulo, v. 42, n. 4, p. 475-485, dez. 2006.

MINISTÉRIO DA SAÚDE. AGÊNCIA NACIONAL DE VIGILÂNCIA SANITÁRIA. ORGANIZAÇÃO PAN-AMERICANA DA SAÚDE/ORGANIZAÇÃO MUNDIAL DA SAÚDE. Seminário Internacional Perspectivas para o fortalecimento dos mercados de medicamentos similares e genéricos em países em vias de desenvolvimento. In: Relatório Final Série Medicamentos e outros insumos essenciais para a saúde. Brasília: MS. ANVISA. OPAS/OMS, 2005.

MONEDERO, Emílio Diez. A biotecnologia na indústria farmacêutica. (196-203) In: CASABONA, Carlos Maria Romeo. Biotecnologia, Direito e Bioética: perspectivas em Direito Comparado. Belo Horizonte: Del Rey e PUC Minas, 2002.

NACIONES UNIDAS. Propiedad intelectual y Derechos Humanos: Queda ahora clara la diferencia? Evaluación de la Observación General № 17 (2005) del Comité de Derechos Económicos, Sociales y Culturales, 2005. Disponível em: <http://www.3dthree.org/pdf_3D/3D_CDESC_DDHH_PI.pdf>. Acesso em: 17 mar. 2012. 
OBJETIVOS DE DESENVOLVIMENTO DO MILÊNIO BRASIL. Os Objetivos de Desenvolvimento do Milênio. Brasília. 2000. Disponível em: <http://www.odmbrasil.gov.br/os-objetivos-de-desenvolvimento-do-milenio\#portletnavigation-tree>. Acesso em: 13 abr. 2018.

ORGANIZAÇÃO DAS NAÇÕES UNIDAS. Objetivos de Desenvolvimento do Milênio. Brasil, 2000. Disponível em: <https://nacoesunidas.org/tema/odm/>. Acesso em: 13 abr. 2018.

ORGANIZAÇÃO DAS NAÇÕES UNIDAS. Objetivos de Desenvolvimento Sustentável. Brasil, 2015. Disponível em: <https://nacoesunidas.org/pos2015/agenda2030/>. Acesso em: 12 mai. 2018.

PIANETTI, Gerson Antônio. Registro e autorização: atendimento aos requisitos mínimos de qualidade, eficácia e segurança. Série Uso Racional de Medicamentos: fundamentação em condutas terapêuticas e nos macroprocessos da Assistência Farmacêutica. OPAS/OMS. Brasília, v.1, № 6, p.1-8, abril 2016. Disponível em: <http://www.paho.org/bra/index.php?option=com_docman\&view=download\&category_slug =serie-uso-racional-medicamentos-284\&alias=1534-registro-e-autorizacao-atendimento-aosrequisitos-minimos-qualidade-eficacia-e-seguranca-4\&Itemid=965>. Acesso em: 17 abr. 2018.

PIETRO, Maria Sylvia Zanella Di. Direito Administrativo. 25 ed. São Paulo: Atlas, 2012.

PIMENTEL, Luis Otávio; BARRAL, Welber (Org). Propriedade Intelectual e desenvolvimento. Florianópolis: Fundação Boiteaux, 2007.

PORTAL MÉDICO. CPI dos Medicamentos. A urgência de uma política nacional de medicamentos. In: Jornal Medicina, jan. 2000. Disponível em: <http://www.portalmedico.org.br/jornal/jornais2000/012000/cpi.htm>. Acesso em 21 mai. 2018.

REZENDE, Kellen Santos. Produção: a corda bamba entre o mercado e as necessidades de saúde pública. Série Uso Racional de Medicamentos: fundamentação em condutas terapêuticas e nos macroprocessos da Assistência Farmacêutica. OPAS/OMS. Brasília, v.1, № $4, \quad$ p.1-6, março 2016.2 Disponível em: $<$ http://www.paho.org/bra/index.php?option=com_docman\&view=download\&alias=1532producao-a-corda-bamba-entre-o-mercado-e-as-necessidades-saude-publica$2 \&$ category_slug=serie-uso-racional-medicamentos-284\&Itemid=965>. Acesso em: 05 abr. 2018.

SÁ JUNIOR, Luis Salvador de Miranda. Desconstruindo a definição de saúde. In: Jornal do Conselho Federal de Medicina (CFM). Brasília, p.15-16, jul/ago/set de 2004.

VIZZOTO, Alberto. A função social das patentes sobre medicamentos. São Paulo: LCTE, 2010. 
WORLD HEALTH ORGANIZATION. The Rational Use of Drugs. In: Report of the Conference of Experts. Nairobi: WHO, nov. 1985. Disponível em: <http://apps.who.int/medicinedocs/documents/s17054e/s17054e.pdf>. Acesso em 10 abr. 2018.

ZANIN NETO, Armando. Propriedade Intelectual e Direitos Humanos: A inovação tecnológica pode favorecer o desenvolvimento social no Brasil? 2010. 178f. Dissertação (Mestrado) - Programa de Pós-Graduação em Direito, Universidade Metodista de Piracicaba, Piracicaba, 2010. Disponível em: <https://www.unimep.br/phpg/bibdig/pdfs/docs/15062011_101329_armandozaninneto.pdf>. Acesso em: 13 abr. 2018. 